\title{
POR ACASO SOU NEGRA? NA AMAZÔNIA, EM BELÉM, NO ENCONTRO COM OUTREM
}

\author{
AM I BLACK?: IN AMAZONIA, BELÉM, MEETING WITH OTHERS
}

\author{
Tainara Lúcia Pinheiro ${ }^{1}$ \\ Carmem Izabel Rodrigues ${ }^{2}$
}

\begin{abstract}
Resumo
Neste artigo, objetivamos compreender as influências dos processos de colonização na Amazônia brasileira nas identificações raciais de mulheres negras. A metodologia de pesquisa, baseada em etnografia de abordagem fenomenológica, permite pensar a influência colonial nos processos miscigenatórios e de classificação identificatória referente a questões de raça/cor explicitadas nos censos e na vida cotidiana. $O$ artigo reflete sobre as maneiras como a negritude amazônida é muitas vezes invisibilizada e questionada na região, partindo da crença na existência de uma morenidade local, e fora da região, por não amazônidas que por vezes compartilham, no encontro, a frustração com as expectativas criadas por uma representação do que é Amazônia e isso contribui para a deslegitimação da identificação racial da população negra daqui, que, por entender sua diferença também no âmbito regional, inclusive na maneira como a morenidade tem força enquanto discurso local, prefere uma classificação identificatória híbrida, um ser afroamazônida.
\end{abstract}

Palavras-chave: Identificação; Negra; Belém; Amazônia.

\begin{abstract}
In this article, we aim to understand the influences of colonization processes in the Brazilian Amazonia on the racial identifications of black women. The research methodology, based on ethnography with a phenomenological approach, allows us to think about the colonial influence in the miscegenatory processes and in the identifiable classification related to race / color issues explained in the censos and in everyday life. The article reflects on the ways in which Amazonian blackness is often made invisible and questioned in the region, based on the belief in the existence of a local morenity, and outside the region, by non-Amazons who sometimes share, at the meeting, the frustration with expectations created by a representation of what the Amazonia is and this contributes to the delegitimation of the racial identification of the black population here, who, understanding their difference also at the regional level, including the way that morenity has strength as a local discourse, prefers a hybrid identifiable classification, an afroamazon being.
\end{abstract}

Keywords: Identification; Black; Belém; Amazonia.

\section{Resumen}

En este artículo, nuestro objetivo es comprender las influencias de los procesos de colonización en la Amazonia brasileña en las identificaciones raciales de las mujeres negras. La metodología de investigación, basada en la etnografía con un enfoque fenomenológico, nos permite reflexionar sobre la influencia colonial en los procesos miscegenatorios y en la clasificación de identificación relacionada con cuestiones de raza / color explicitadas en los censos y en la vida cotidiana. El artículo reflexiona sobre las formas en que la negritud amazónica a menudo se vuelve invisible y cuestionada en la región, basándose en la creencia en la existencia de una morenidad local, y fuera de la región, por personas no amazónicas que a veces comparten,

\footnotetext{
1 Mestranda em Sociologia e Antropologia pelo Programa de Pós-graduação em Sociologia e Antropologia da Universidade Federal do Pará. Pesquisadora no grupo de estudos e pesquisa NosMulheres. Integra o Grupo de Estudos Afro-Amazônico (GEAM/UFPA). E-mail: tainaraluc@ hotmail.com

${ }^{2}$ Doutora em Antropologia. Professora do Programa de Pós-graduação em Sociologia e Antropologia (PPGSA) da Universidade Federal do Pará. Participa dos Grupos de Pesquisa: GEMP - Grupo de Estudos sobre Mercados Populares-UFPA e TAMBOR - Grupo de Estudos sobre Carnaval e Etnocenologia - ETDUFPA. E-mail: $\underline{\text { cizbel@gmail.com }}$
} 
en la reunión, la frustración con las expectativas creadas por una representación de lo que es la Amazonia y esto contribuye a la deslegitimación de la identificación racial de la población negra aquí, quien, entendiendo su diferencia también a nivel regional, incluida la forma en que la morenidad tiene fuerza como discurso local, prefiere una clasificación híbrida identificable, un ser afroamazonida.

Palabras-clave: Identificación; Negra; Belém, Amazonia.

\section{INTRODUÇÃO}

“Por acaso sou negra?”... Muitas coisas podem justificar essa dúvida, inclusive a história de um país. Recorramos, então, a uma parte da história do nosso: durante o processo colonial, a Amazônia estava vinculada diretamente ao rei, em Lisboa. É só em 1823, um ano depois da independência do Brasil, que o Grão-Pará adere ao Estado brasileiro e a região é formalmente integrada. Segundo Salles (2005, p.108), durante a colonização, grandes migrações portuguesas foram direcionadas para a Amazônia, e esses grupos (continentais, ilhéus e da praça de Mazagão, na África) originaram diversos núcleos urbanos. Migrantes de outros lugares também habitavam a cidade, como franceses, ingleses, holandeses e judeus. As ordens religiosas que vieram para a região também trouxeram europeus (italianos, espanhóis, alemães e franceses, entre outros), de modo que tanto biológica quanto culturalmente estão presentes, na população, as marcas desses encontros, as marcas do branqueamento, as marcas da colonização.

Nesse encontro colonial outras marcas foram sendo acrescidas, gerando continuamente um processo de miscigenação que, segundo Flávio Gomes (2001, p.31), deve ser considerado na busca de interpretações sobre essa "mistura de cores na floresta". E se a historiografia brasileira pouco destacou a presença africana na Amazônia, diversas pesquisas regionais apontaram essa presença e sua importância na formação das populações presentes nessa região ${ }^{3}$.

Até o século XVII a base da economia na Amazônia era extrativista. No final do século XVIII era comum que indígenas, africanos e seus descendentes compartilhassem o mesmo espaço, conformando um campesinato; as fugas de escravos eram muitas vezes estimuladas por indígenas que apontavam rotas de fuga e compartilhavam contatos comerciais, que eram intensos na área do Solimões entre diversas etnias (GOMES, 2001, p.30-31). Já na segunda metade do século o projeto pombalino decretou o fim da escravidão indígena e do poder temporal dos missionários na região (p.37). Nesse contexto, o conflito entre e Estado português e os jesuítas se acirrava e no mesmo período é incrementado o tráfico africano (p.33).

Flávio Gomes (2001) nos diz que o sistema de plantation, açúcar e tabaco, principalmente, foi o primeiro investimento na Amazônia em começo do período colonial, investimento que fracassou por fatores como: baixo investimento de capital, mão de obra africana mais cara aqui do que na Bahia e em Pernambuco, questões geográficas e epidemias. As produções foram então direcionadas para consumo interno e o extrativismo concentrou-se nas "drogas do sertão" (p. 31). A força dos mercados de açúcar em Pernambuco e na Bahia e o algodão, depois, no Maranhão, demandavam muita mão de obra e, por isso, a entrada de africanos na região amazônica no século XVII e começo do XVIII fora menor, o que gerou uma

\footnotetext{
${ }^{3}$ Sobre o assunto ver, entre outros: Salles (2005 [1971]); Vergolino-Henry; Figueiredo (1990). 
série de conflitos entre os grupos interessados. É só depois da segunda metade do século XVIII que se intensifica a entrada de negros africanos no Grão-Pará. Na comarca do Rio Negro, atual Amazonas, trabalhadores indígenas começaram a ser substituídos por trabalhadores negros (GOMES, 2001, p.32-33).

Salles (2005) afirma que no Pará e no Maranhão é marcante a presença das culturas sudanesas e banto em regime de solidariedade cultural pela condição de escravos que lhes fora imputada, e um tanto mais individual é a presença do negro mina, cuja cultura ainda se mantém conservada principalmente no Maranhão ${ }^{4}$. Para ele, alguns fatores históricos como proibição do tráfico, abolição da escravatura, migração de nordestinos ${ }^{5}$ para a Amazônia e outros acabaram por fazer com que o contingente de pessoas negras aqui fosse diminuído, considerando que outras identificações eram construídas, identificações essas advindas de processos miscigenatórios. A maneira como essas identificações são construídas é um ponto de partida para pensarmos a pergunta que orienta este artigo: por acaso sou negra?

A discussão sobre identidades e identificações é antiga e amplamente desenvolvida nas ciências humanas. Cardoso de Oliveira (2006), afirma que as noções de identidade comportam as dimensões pessoal (individual) e social (coletiva), sendo que ambas se conectam na construção de um mesmo fenômeno que se apresenta de diferentes formas. Em outras palavras, uma identidade social é construída por processos de identificação, a identificação como identidade em processo. A identidade, social e pessoal, é, por um lado, uma definição de outras pessoas em relação ao indivíduo. Mas é também, por outro lado, uma autoatribuição, um processo de autoconhecimento, identificação e auto representação identitária. Como afirma Maldonado (2005, p.482-483), "a identidade deriva de um processo de múltiplas identificações, de uma constante "negociação" das contradições e dos conflitos determinados por essas mesmas identificações".

A ideia de identidade como algo em construção ou a ser construído é comum, também, na sociologia de Castells (2008), que afirma que relações de poder, origem, entre outros aspectos da vida, influenciam na construção social da identidade. Essa visão é compartilhada por Woodward (2014), para quem todo tipo de identidade é relacional, requer antítese, é marcada pela diferença e essa marcação pode levar a hierarquizações; aqui, a diferença aparece como exclusão. A autora afirma que toda construção identitária é simbólica e social, marcada pela diferença e dependente do espaço e momento histórico em que é construída, uma vez que, por meio desses atravessamentos, algumas diferenças são vistas como mais importantes que outras.

Segundo Silva (2014, p.76), identidade e diferença são dependentes entre si; ambas são criações da linguagem, criações sociais e culturais, portanto; são atos de linguagem, precisam ser nomeadas, "em contraste, com a ideia de diferença como produto, a noção de diferença como operação ou o processo básico

\footnotetext{
${ }^{4}$ Essas especificações de etnia, no entanto, pouco interessavam para o regime escravista. Escravo era escravo e ponto. Por isso, Salles (2005) só encontra essas informações após longa e comprometida pesquisa histórica.

${ }^{5}$ Ressaltamos que, diferentemente do que aconteceu no projeto imigrantista, a migração de nordestinos para cá não tinha intenção de branqueamento do contingente populacional, mas de estabelecimento de força de trabalho no período da borracha. Sair de suas regiões, para esses migrantes nordestinos, também era alternativa para os problemas causados pela seca naquele período.
} 


\section{Por acaso sou negra?}

\section{Na Amazônia, em Belém, no encontro com outrem}

de funcionamento da língua e, por extensão, de instituições culturais e sociais como a identidade, por exemplo". Para o autor, essa luta por "afirmação da identidade e a enunciação da diferença" traduz "os desejos dos diferentes grupos sociais, assimetricamente situados, de garantir o acesso privilegiado aos bens sociais [...] aos recursos simbólicos e materiais da sociedade", de modo que "identidade e a diferença estão, pois, em estreita conexão com relações de poder" (p.81). Mas produzem também, ao mesmo tempo e no próprio ato de enunciação, um espaço social de luta por reconhecimento (BAUMAN, 2001; CARDOSO DE OLIVEIRA, 2006), um campo de disputas, de afirmação (de si) ou negação (do outro) em permanente dinamismo conflituoso.

Isso nos permite entender os sistemas de representação que possibilitam a análise da relação entre a cultura e o significado da ação humana. As diferenças são estabelecidas por meio de sistemas classificatórios de apreensão das relações e entre sujeitos e grupos sociais e as coisas ou produtos por eles disputados; segundo Woodward (2014, p.40) "um sistema classificatório aplica um princípio de diferença a uma população de uma forma tal que seja capaz de dividi-la (e a todas as suas características) - nós e eles".

Neste artigo, buscamos refletir sobre as influências dos processos de colonização na Amazônia brasileira nas identificações raciais de mulheres negras que de alguma maneira atravessaram a Rede de mulheres Negras ${ }^{6}$. A metodologia de pesquisa é etnografia de abordagem fenomenológica, realizada entre os anos de 2015 e 2020 em Belém do Pará, adotando os recursos de histórias de vida para acessar as experiências de mulheres, por meio de entrevistas semiestruturadas. Para pensar essas identificações, partimos das discussões conceituais das identidades sociais e individuais, e recorremos à pesquisa histórica sobre as classificações raciais no Brasil, como veremos a seguir.

\section{IDENTIFICAÇÕES, CLASSIFICAÇÕES...}

E nas negociações de definições identificatórias raciais ou de cor existem diferenças e especificidades considerando os espaços em que são apresentadas ou reivindicadas. A maneira de classificar e a própria discussão sobre classificação também passa por negociações e muda no tempo; isso pode ser analisado a partir de censos demográficos. Em 1793, a cidade de Belém contava com 8.573 habitantes, sendo 3.051 escravos (negros) que, somados a 1099 pretos, índios e mestiços (libertos), perfaziam 48,4\% da população (SALLES, 2005, p.95). Esse total de mestiços e escravos libertos continuou crescendo em números absolutos até o período de 1822, enquanto o número de brancos caiu. Comparando os dados que o autor traz de 1793 e 1822, proporcionalmente, percebemos aumento percentual da população preta (escrava): em 1793 é de 35,6\%, já em 1822 passa a ser de 45,9\%; segundo esses dados, o número de libertos (índios,

\footnotetext{
${ }^{6}$ Rede de Mulheres Negras é um grupo de mulheres negras que nasceu na UFPA mas não se restringe aos muros da universidade. Usando a linguagem do parentesco para o trato entre iguais - "manas", "irmãs" -, as mulheres que integram esse grupo se fortalecem por meio de trocas de textos, ideias e afeto, auxiliando umas às outras no enfrentamento cotidiano às opressões vividas. Foram realizadas entrevistas com 10 mulheres que estão ou estiveram, em algum momento, participando dessa rede.
} 
pretos, mestiços) cai, passando de 12,8\% para 8,8\% - entendendo por mestiço, aqui, múltiplas combinações étnicas, os não "africanos natos"7.

Da população no Grão-Pará de 1849, o contingente livre e escravo era de 186.062 almas do total de 204.662 pessoas, não inclusos indígenas dos aldeamentos, malocas e missões ${ }^{8}$ (SALLES, 2005, p.98-99). Isso significa dizer que 90,2\% da população nesse período era de não brancos, os pretos (escravos) e libertos (índios, pretos e mestiços). O relatório de Estatística da Província, de 1851, apresentou uma população total de 209.213 habitantes, sendo 175.140 livres e 34.073 escravos: 16.950 homens e 17.123 mulheres. Ali, constatou-se um aumento de 23.230 na população livre e diminuição de 179 escravos. A diferença entre os dados indica o aumento da população livre e a diminuição da população escrava. De 1854 para 1862 a proporção passou a ser de um escravo para cada seis livres no Pará (SALLES, 2005, p.101) ${ }^{9}$.

Sobre a composição étnica da população amazônica, Salles aponta que ao passo que as identificações Brancos, Caboclos e Pardos e Mestiços ${ }^{10}$ crescem, a de Pretos diminui no intervalo dos anos. E esse padrão avança no tempo. Durante a formação de colônias por aqui, em meados do século XIX, Belém e Manaus eram foco por conta da borracha e muitos migrantes saiam das colônias para habitar as capitais. Reflexo disso, em 1950 a população de Belém era composta por 254.949 pessoas, sendo 109.721 brancas, 132.941 pardas, 11.652 negras e 201 amarelas. Em 1822, o total de Pretos em Belém era de 46\% e em 1950 esse número passa a ser de 2,9\% (SALLES, 2005, p.103-104).

Pessoas vinham para a região pelos mais diversos motivos e das mais diversas localidades, mas, enquanto corrente migratória, só os portugueses tiveram força de continuidade. Ainda que não favorecendo o Norte, a política migratória do século XIX direcionou para Santarém colonos americanos e para contingentes populacionais menores foram os portugueses, os italianos e espanhóis. Os árabes, sírios e libaneses, conhecidos como turcos, chegaram um pouco depois (GOMES, 2001).

Todas essas políticas coloniais proporcionaram diferentes encontros que tornavam a classificação por raça/cor cada vez mais confusa. O que não era confuso para ninguém e isso pode ser visto na cor das pessoas que ocupavam os espaços de poder, era quem poderia ou não estar em posições e espaços de privilégio. Ainda que tipificar fosse difícil, nas desigualdades da vida cotidiana era explícito quem era branco e quem não era. Os não brancos compartilhavam a margem em maior ou menor medida. Abaixo, o quadro de

\footnotetext{
${ }^{7}$ Importante ressaltar que os relatórios desses censos que Salles analisa não revelavam a realidade social, uma vez que intencionalmente os senhores não declaravam pelo menos metade dos escravos que possuíam para não pagarem impostos (SALLES, 2005, p.97). Por outro lado, os processos de resistência, evasão para mocambos e sucessos da cabanagem também influenciam na diminuição desse contingente populacional (p.100).

${ }^{8}$ Nesse ano a população escrava do Grão-Pará era de 34.216 pessoas (17.471 homens e 16.736 mulheres), com 19.189 em Belém, sendo 9.637 homens e 9.552 mulheres (SALLES, 2005, p.98).

9 Tavares Bastos (apud SALLES, 2005, p.101), com base no relatório do presidente Francisco Brusque, aponta a diferença entre população livre e escrava em 1854 (167.909 livres, 30.847 escravos) e 1862 (185.300 livres, 30.623 escravos).

10 "Na nomenclatura oficial do IBGE, os mestiços são designados pardos, palavra ambígua, mas de uso generalizado, que engloba diversas categorias de mestiços" (SALLES, 2005, p.104).
} 
Diegues Junior (1963), replicado a partir de Salles (2005), apresenta as classificações feitas a partir de miscigenação:

Quadro 1: Classificações a partir da miscigenação

$\begin{array}{lll}\text { 1. } & \text { Branco } & \text { Branco x Branco } \\ \text { 2. Mulato } & \text { Branco x Negro } \\ \text { 3. Mameluco } & \text { Branco x Índio } \\ \text { 4. Crioulo } & \text { Negro x Negro } \\ \text { 5. Cafuzo, também } & \text { Negro x Índio } \\ \text { chamado curiboca } & \\ \text { 6. Cabra } & \text { Negro x Mulato } \\ \text { 7. Caboclo } & \begin{array}{l}\text { Índio x Índio } \\ \text { 8. Pardo }\end{array} & \begin{array}{l}\text { Descendentes dos cruzamentos secundários entre mulato x } \\ \text { mulato, crioulo x crioulo, mulato x mameluco etc., onde vigora } \\ \end{array} \\ & \text { mais nítida a pigmentação morena ou tendendo à escura. }\end{array}$

Fonte: Diegues Junior (apud SALLES, 2005, p.122).

Parece que ainda hoje adotamos a mesma linguagem da tabela anterior para classificar outros e, talvez, a nós mesmos quando se trata de ser pardo: descendentes dos cruzamentos secundários entre mulato $\mathrm{x}$ mulato, crioulo x crioulo, mulato x mameluco etc., onde vigora mais nítida a pigmentação "morena" ou tendendo à escura.

As maneiras de classificar de hoje, tanto em âmbito nacional quando regional, são influenciadas por processos históricos. O Brasil, construído de modo a se amparar em visões racistas e escravocratas, construiu um projeto de nação para exterminar a população negra e isso influenciou diretamente nas classificações identificatórias, inclusive na região amazônica, que foi sistematicamente submetida à exploração territorial e de recursos, o que fez com que pessoas de diferentes lugares do mundo chegassem por aqui e aqui fizessem morada, ainda que temporariamente. Falar de identificações raciais na Amazônia é complexo e o é graças aos diversos processos de colonização que nos foram impostos; mas tanto mais complexo é, mais necessário se torna, uma vez que a complexidade do tema não diminui a intensidade das violências sofridas por uma população que tem suas identificações impedidas.

\section{COLONIZAÇÕES E CLASSIFICAÇÕES IDENTIFICATÓRIAS}

No censo demográfico de 2010 (IBGE), o primeiro em que a população declarada negra é maior que a branca, o Pará, estado mais negro do Brasil de acordo com o IBGE, foi onde a maior parte da população se declarou parda. Quase $70 \%(69,5 \%)$ das pessoas por aqui se dizem pardas, 21,8\% identificam-se como brancas e apenas $7,2 \%$ se identificam como pretas. Apenas Roraima tem população em que o número de pessoas declaradas brancas $(20,9 \%)$ é menor que o Pará. Agora, tratando-se de população preta, o Pará fica atrás de 10 unidades federativas ${ }^{11}$.

\footnotetext{
${ }^{11}$ Bahia (17,1\%), Rio de Janeiro (12,4\%), Maranhão (9,7\%), Minas Gerais (9,2\%), Tocantins $(9,1 \%)$, Sergipe $(8,9 \%)$, Amapá $(8,7 \%)$, Espírito Santo (8,3\%), Distrito Federal (7,7\%) e Mato Grosso (7,6\%) (IBGE, Censo Demográfico, 2010).
} 


\section{Por acaso sou negra? \\ Na Amazônia, em Belém, no encontro com outrem}

Ainda vigora, aqui no Pará e especificamente em Belém, a ideia de que somos mestiços, pardos. Branco, branco, não conseguimos ser, de fato. Enquanto cidade, o discurso é de que preto não queremos ser - esse é o discurso das elites brancas por aqui. Pardos somos, então, ou isso que cabe no ser pardo e no censo não se apresenta: somos morenos. De acordo com Paixão e Carvano (2008), das pessoas que participaram da pesquisa PME/IBGE de julho de 1998, 77\% se declararam pardas, 14\% brancas e $6 \%$ pretas. De maneira geral, diferentes pesquisas apresentadas pelos autores apresentam uma proximidade entre declarações de si enquanto pardos e morenos, como no exemplo seguinte:

Charles Wood (1991), baseado nas séries históricas dos Censos Demográficos brasileiros entre 1950 e 1980, procedeu algumas projeções demográficas dos grupos de cor ou raça da população brasileira obtendo resultados que confirmam a existência de reclassificações de cor ou raça no período. Contudo, o mesmo autor salienta que esta reclassificação era mais provável dos grupos pretos para os grupos pardos, estimando que $38 \%$ das pessoas pretas que tinham entre 14 a 29 anos de idade, em 1950, teriam mudado, em 1980, para grupo de cor, pardo. No que tange à passagem dos grupos brancos e pardos, os mesmos cálculos feitos por Wood estimaram que os limites que separavam ambos os grupos eram mais estáveis ao longo do tempo, na realidade (e contrariando a hipótese do branqueamento dos pardos), tendo ocorrido uma proporção de $9 \%$ de brancos que passaram a se declarar pardos (PAIXÃO e CARVANO, 2008, p.49).

Motta-Maués (1997, p.31) aponta, em sua tese, uma angústia que também é nossa, quando afirma:

Não sei de lugar algum desta nossa América em que querer "ser branco" seja um ideal e uma meta tão fortes, a ponto de fazer disso não só um desejo, mas uma espécie de ilusão vivida e vivida realmente. Não falo aqui do imaginário, do simbolismo, da estética, do culto enfim da ou à brancura - que isso partilhamos com todos os latinos -, mas do estranho "daltonismo" que permite a alguém de raça e cor negras se "ver" (como) branco, e não só se ver, mas acreditar piamente que é branco. Estranho jogo de visibilidade (branca) / invisibilidade (negra) que nos faz a todos no máximo "morenos".

Segundo Kilomba (2019, p.19), a língua portuguesa é intimamente ligada a terminologias coloniais que muitas vezes caem na dicotomia de serem racistas ou animalizantes (ou ambos); esses termos estavam intimamente relacionados, no contexto colonial, “ às políticas de controle da reprodução e proibição do 'cruzamento de raças', reduzindo as 'novas identidades' [...] à condição de animal irracional, impuro". Os exemplos mais comuns são os termos mestiça/o, mulata/o; o primeiro usado para definir o cruzamento de duas raças diferentes; o segundo para definir o cruzamento entre duas espécies animais diferentes; ambos originam um animal considerado impuro, inferior (p.19). Partindo da perspectiva de Kilomba, sobre o significado de termos que "revelam uma profunda falta de reflexão e teorização da história e herança coloniais e patriarcais [e que] na língua portuguesa continuam ancorados [em] um discurso colonial e patriarcal...” (KILOMBA, 2019, p.14), trazemos a categoria morena/o como uma identidade em questão/reflexão.

E morena, é o quê? É produto do racismo à brasileira, da tentativa de eufemizar a violência do embranquecimento enquanto projeto de nação. A língua cria e perpetua relações de poder e de violência, definindo lugares de identidades, informando-nos quem pode representar a real condição humana 
(KILOMBA, 2019). A palavra "morena” é construída a partir de "um jogo de palavras doces e amargas”, nos termos de Kilomba (2019, p.162), jogo esse que não apenas dificulta a identificação do racismo, mas é a expressão do racismo em si. A palavra sustenta a ideia de que um corpo não é "tão preto assim", é uma "preta diferente", um corpo que tem algo a mais, "apesar de". Categorias identificatórias como morenidade funcionam como possibilidade de escapar do que ofende: a negritude. É um tipo de subcategoria que retira a pessoa de um lugar de rejeição, mas, ao mesmo tempo, lembra a ela que não pode ser totalmente aceita. É mestiçada, está na posição no limiar, no meio da hierarquia entre negros de pele clara e negros de pele escura e isso é reafirmado muitas vezes por pessoas brancas em um tipo de violência que não está na tipificação, mas na dissimulação presente nessa maneira de tipificar.

Kilomba (2019) identifica essa invisibilização do visível, a negação da identificação como negra pelo outro que é branco, como uma maneira de não conseguir admitir a negritude como algo positivo, uma maneira de não ter de lidar com o fato de que as diferenças são explicitadas por meio de processos discriminatórios. Não aprendermos a lidar com as diferenças acaba impedindo de perceber que o que nos separa não são as diferenças em si, mas nossa recusa em percebê-las e reconhecer que as nomeamos de maneira errada, o que acaba causando desvios em nossos comportamentos e expectativas. Desfazer essa distorção é, para cada pessoa, tarefa de uma vida inteira, entendendo que essas diferenças não são barreiras insuperáveis (LORDE, 2019). Explorar as diferenças pode ser o primeiro passo para uma mudança criativa no fluxo da vida.

A institucionalização da rejeição à diferença é fundamental em economia que precisa de forasteiros como superávit, economia baseada em lucro; nós, que somos membros dessa economia, fomos programados para reagir à diferença com ódio (LORDE, 2019). Quando a pessoa negra cresce aprendendo que negritude está relacionada às coisas negativas, tudo que ela não desejará é ser negra. O que se deseja, com todas as forças, não é extirpar de si a cor da pele, a textura do cabelo, os traços do corpo, mas tudo aquilo que o olhar do outro produz na experiência vivida do negro: não se deseja deixar de ser negro de fato, o que se quer é não sofrer racismo, não ser visto como ameaça. É esse embate que constrói a alienação identificatória.

Fábio Castro (2011, p.213) enfatiza a produção de metáforas sobre a identidade amazônica presentes em diversas obras poético-literárias de autores locais que tem vivenciado essa experiência de pensar essa identidade com base em suas próprias experiências; em busca do que chamou de "sínteses da identidade amazônica". Essa identidade configura-se como um "sentir coletivo" subjetivamente vivenciado de pertencimento a um espaço-lugar "inventado no seu uso", concebido pelos artistas como uma região (Amazônia), que formou "um tipo humano híbrido", o caboclo, não como uma essência, mas como uma referência identitária (fronteiriça) dessa “moderna tradição amazônica (p.213-237).

Destacamos, entre os trechos ilustrativos de artistas locais que Castro (2011) utilizou para falar dessa identidade, a letra da canção de Chico Sena "Flor do Grão Pará, por sua referência à cidade de Belém como 
"menina morena"12. Esta síntese remete, segundo Castro, ao caboclo como "um marco sintetizador da região" [...] referente essencial de uma 'identidade' geral amazônica"; por outro lado, "significa, antes, o campesinato ribeirinho amazônico que um grupo étnico, biológica ou politicamente identificado" (p. 231). Embora o autor destaque, de forma precisa, nas letras analisadas, a presença dessa identidade cabocloribeirinha na cidade $^{13}$, queremos destacar, na letra da canção, o aspecto da morenidade, que será cada vez mais enfatizado nos estudos locais sobre nossa formação étnico-racial. Em Belém do Pará, predomina cada vez mais a ideia de que somos uma cidade morena para um povo moreno ${ }^{14}$.

Entre as máscaras (Fanon, 2008) disponíveis para identificação de si, nessa cidade, esbarramos na máscara de morenidade, construção regional que nasce como estatuto simbólico positivo associado à "brasilidade" em termos de explicação para miscigenação (VAZ SILVA, 2007). Aqui temos a morenidade como identificação social que nomeia um tipo de identidade coletiva regionalizada (RIBEIRO, 2012), que aparece inclusive como título para a cidade:

Cidade tem cor? Belém tem. Uma mal definida e mal resolvida. À capital paraense, foi conferido o título de Cidade Morena, que se refere à cor da pele da maior parte da população da cidade, essa cor que tem um tom meio escuro, meio marrom, até pardo, talvez meio pálido. Negro. Negro? [...] O moreno pode mascarar uma identidade [...] que ainda sofre os impactos de séculos de abusos coloniais e ainda não conseguiu refletir sobre si mesma, sobre suas origens e raízes. E por isso não conseguiu se assumir. Por que Belém não é cidade negra? (SARRAF, 2016. s/p).

Atentamos para este perfil moreno, para sustentar a influência da experiência de descoberta de ser negro, pois, segundo Conrado, Campelo e Ribeiro (2015), a cor morena é articulada discursivamente para que a preta passe a não mais existir e, talvez, para solucionar essa nossa dúvida identificativa: sabemos que não somos "índios" nem brancos, e as elites brancas não querem negros. E apesar da valorização simbólica do caboclo nos trabalhos dos artistas locais (como vimos antes na análise de Castro), esta não é uma categoria de auto atribuição da população urbana; é muito mais uma categoria de alteridade, que fala sempre de um "outro amazônida" que parece viver longe dos grandes e médios centros urbanos, nas margens dos rios e nos interiores das matas, o ribeirinho, o rural, o índio; trata-se de uma categoria de acusação, e não identificação de si; como afirma Rodrigues (2006), o caboclo é a fantasmagoria que assombra o amazônida urbano.

Se nada disso podemos ser ou não querem que sejamos, seremos, então, o que? Nas entrevistas realizadas com participantes da Rede de Mulheres Negras, foi possível perceber essa dúvida persistente, na avaliação que sofriam sobre sua cor; a não identificação por outros como negra, tendo como principal motivo

\footnotetext{
${ }^{12}$ Rosa flor vê quanta mangueira / E o cheira-cheira do tacacá / Meu amor ata a baladeira / Embalança a beira do riomar / Belém, Belém acordou a feira / Que é bem na beira do Guajará / Belém, Belém, menina morena / Vem Ver-oPeso do meu cantar / Belém, Belém és minha bandeira / És a flor que cheira do Grão-Pará. (Chico Sena, Flor do GrãoPará (CD); apud CASTRO, 2011, p.235-236).

${ }^{13}$ Embora seja um tema altamente valorizado por artistas e intelectuais locais, o lugar social do caboclo tem uma "longa tradição segregatória" (CASTRO, 2011, p.232). Sobre o assunto ver Wagley (1977) e Lima-Ayres (1999).

${ }^{14}$ Sobre o tema, ver Conrado; Campelo e Ribeiro (2015), Sarraf (2016) e Câmara (2017), entre outros.
} 
a cor da pele, em comparação com outras pessoas "mais" negras trazia, de forma reflexiva, essa indefinição, como uma questão não resolvida. Essa dúvida fica explícita na fala de Natalina ${ }^{15}$, uma das entrevistadas, quando afirma que

\begin{abstract}
... sempre ficava aquela coisa de pensar muito a negritude por conta da cor e por muito tempo eu fiquei assim também "nossa, será que eu sou ou será que eu não sou negra?", né? Porque as pessoas te olham e "não, mas tu não é", aí tu fica assim "meu Deus, eu não sei o que eu sou". (Entrevista, 2016).
\end{abstract}

Esse "continuum de cor", nos termos de Hasenbalg (1979), é o que se conceitua hoje em espaços de militância como colorismo, que versa sobre sujeitos que estão em posição intermediária na demarcação racial, "entre o ser negro e o ser branco, sobretudo aqueles que em termos de estereótipos apresentam elementos da caracterização negra, mas predomina a cor de pele clara" (LOPES, 2016, p.156). Natalina argumenta que "pelo fato de eu ter a pele clara também fica muito essa questão da negritude em jogo, sabe? "Que tu és ou tu não és?”, “Tu és morena de cabelo crespo?” (Entrevista, 2016).

Por ter a pele mais clara, os tipos de opressão que esses sujeitos experienciam são diferentes (LOPES, 2016). Cida, outra entrevistada, relata sobre essa questão:

Eu tenho privilégios por questões da cor mesmo, eu sou lida como a quase branca, só que tu nunca vai ser branca [...] Conviver com pessoas brancas quase metade do tempo é de certo modo tu ter aqueles olhares, não é? Eu lembro que na minha turma era eu e uma outra moça que é de pele mais escura do que eu, então de algum modo eu percebia que os olhares eram muito mais voltados para ela. Eu lembro de um episódio que um dia a gente tava numa festa e ela deixou o cabelo solto e um colega branco fez uma piadinha relacionando ela a macaco, né? E na época eu já era de movimento, vi aquilo e achei aquilo revoltante, mas sem necessariamente fazer ligação comigo. Eu briguei, xinguei o rapaz pela agressão que ele tinha feito a ela, mas não tinha identificado que aquilo também tinha relação comigo, porque é aquele negócio: por eu entender que eu era morena eu não me identificava com a negritude, então era uma luta deles, que eu não fazia parte, eu não me via como e achava que eu não era vista como negra. (Entrevista, 2016).

Essas identificações podem, também, por vezes ser construídas no processo de classificar um outro, uma vez que "quando se racializa um outro, está-se, ao mesmo tempo, racializando-se a si mesmo, visto que classificar alguém como negro significa quase imediatamente classificar-se a si como branco, pardo, amarelo, ou outra designação" (GUIMARÃES, 2016, p.165). Eu me constituo, portanto, no que me diferencia do outro. Antônio Sérgio Guimarães (2016) aponta, ainda, que é essa a lógica de quem procura um espaço simbólico que se distancie do que não quer fazer parte e detém o poder de classificar quem, dentro desse microcampo, possui alguma distinção, ainda que mínima, dos por eles classificados; algo que justifique ser o outro, e não o si mesmo.

Construções ainda mais específicas desse ser moreno são cotidianamente criadas: morena cor de jambo (mulher negra de pele avermelhada) (VAZ SILVA, 2007), "morenaça" (mulher negra vista como "gostosa") e, entre outras, "morena açaí" (mulher negra de pele escura) (CONRADO, CAMPELO e

\footnotetext{
${ }^{15}$ Como acordado com as entrevistadas, todos os nomes aqui citados são fictícios.
} 


\section{Por acaso sou negra? \\ Na Amazônia, em Belém, no encontro com outrem}

RIBEIRO, 2015). Morena é a cidade, morena é a pele das pessoas, morena é a construção identificatória mais favorável àqueles que por brancos não podem ser identificados, quer seja por si ou pelos outros. Nesse sentido, Zaíta, outra entrevistada, afirma:

Eu não me lembro de ter dito que eu era negra antes desses debates [sobre relações raciais] porque, de fato, eu não via as pessoas falarem sobre isso... A minha mãe não falava sobre isso. O apelido da minha mãe na nossa família é Morena, "Ei Morena!”, a minha família branca sempre conheceu ela como Morena e eu era isso... Morena, Moreninha... Então 'morena' era algo que eu me identificava. Eu não entendia que morena é uma palavra para eufemizar o negro como algo muito negativo. Eu tinha dificuldade de me identificar. Eu não falava que eu era negra. (Entrevista, 2019).

Ressaltamos aqui que o tipo de experiência sobre a qual argumentamos não é ampla em termos de Amazônia e menos ainda geral: falamos da Amazônia belenense. Tratamos, aqui, de uma experiência urbana, considerando que existem diversas realidades para além do foco desta pesquisa; citamos, como exemplo, o relato de uma das interlocutoras de Câmara (2017, p.72):

A gente pode falar mesmo no plural, falar de negritudes na Amazônia, né? Porque ser negra na Amazônia, por exemplo, é ser de uma região de quilombo, ser menina preta nascida no quilombo e pairar na mentalidade urbana como as meninas potenciais pra vir pra cidade ser serviçais, ser babá, limpar banheiro, limpar privada, nunca está nessa posição que eu tô agora, falando como alguém que tem autoridade pra falar disso. Eu sou menina preta quilombola em que jamais foi pensado que eu poderia ocupar o espaço da academia porque a gente sempre foi pensado ou como objeto de pesquisa ou como as potenciais serviçais pra vir pra cidade e isso é para além de classe social inclusive, porque pessoas de família pobre fazem isso, traz as meninas pra virem ser serviçais na cidade e às vezes em uma relação de parentesco inclusive, então pra gente que é negro, importa sim dizer "olha nossa formação é essa, eu faço isso", porque a gente tá quebrando um paradigma porque se esperavam que eu fosse uma babá ou uma empregada doméstica (Grifo nosso).

Nesse depoimento é possível perceber que é no mundo urbano que fica mais nítida a existência de conflitos, afiliações e desigualdades, frutos de afirmações e elaborações de identidades e processos de identificação, seja nos discursos contrários ou nos favoráveis à igualdade e diferença.

\section{CLASSIFICAÇÕES IDENTIFICATÓRIAS E O PODER DE NOMEAR}

As classificações identificatórias influenciam de maneira tão forte os discursos que até mesmo dentro do movimento negro a morenidade pode se apresentar como categoria possível. Outra interlocutora de Flávia Câmara (2017, p.156-157), conta o seguinte:

Minha mãe sempre foi negra, né, minha mãe nunca alisou o cabelo e sempre foi negra na afirmação da identidade e quando a gente ainda não tinha a leitura sobre morenidade, sobre negritude dentro de casa a gente já tinha um debate, mas a gente não tinha uma leitura mais aprofundada então a gente compreendia, a gente achava que nós éramos negras, mas que o tom da nossa pele como nos diferenciava do meu avô, por exemplo, porque ele tem uma pele muito mais escura e a nossa muito mais clara, então nós éramos morenas porque nós éramos um pouco mais claras do que o vovô, mas nós éramos negras [...] em casa eu e minha mãe nunca fomos outra coisa que não negras, curioso, né, é até uma dicotomia digamos assim, nós éramos negras, mas acreditávamos que a questão da morenidade estava associada apenas a um tom de pele e não a uma identidade, quando a gente compreendeu que a questão da morenidade é uma falsa identidade na verdade, é uma identidade atribuída, é uma categoria atribuída, é uma categoria aplicada a pessoa negra para desenegrecer essa 


\section{Por acaso sou negra? \\ Na Amazônia, em Belém, no encontro com outrem}

pessoa, então a gente parou de usar essa expressão porque não, não somos morenas, somos negras.

Esta fala demonstra como que esse processo histórico tem força e influencia na vida cotidiana, no cenário social belenense, na maneira como as pessoas - ainda que militantes - acabam reproduzindo muitas vezes discursos que anulam ou escamoteiam suas identidades. E a maneira como a interlocutora se posiciona, negando a morenidade, é fruto de um processo de compreensão dessa categoria como imposição violenta de anulação de identidades negras. Nas entrevistas, foi possível perceber que esse movimento educador sobre morenidades em Belém vem se expandindo, de modo que, hoje, é bem mais comum que antes que mulheres neguem essa identificação, seguindo exemplos de outras mulheres. É o caso de Zaíta:

Eu lembro muito que a gente teve aqui na UFPA, se iniciou o movimento da Rede de Mulheres Negras, e muitas dessas mulheres já tinham uma vivência, uma experiência de mulher negra muito mais sólida que a minha. Então, elas falavam com muita propriedade 'não, a gente não é morena' e dava aqueles estalos e eu comecei negar o discurso de morenidade, de falar que sou morena... Eu comecei aos poucos. E quando eu comecei a me identificar enquanto negra, eu vi que não tinha resistência das pessoas [do movimento negro] de "égua, mas tu és negra?"... Eu já ouvi “ah, mas tu nem é tão negra assim" e isso me causou um incômodo muito grande, e eu acho que era esse incômodo que eu queria evitar lá no inicio do debate, quando eu comecei a me identificar enquanto negra, que era das pessoas falarem que eu não sou tão negra assim, que a minha pele "não era retinta", que eu "era muito mais morena"... Eu tinha esse receio de alguma forma as pessoas não aceitarem essa minha auto identificação enquanto negra, mas eu sempre fui muito acolhida pelos debates de raça. Tinha mulheres da pele mais clara que a minha e se identificando enquanto negras e a gente fazia esse debate de colorismo, de que a Negritude ela não é "tu é preto ou branco", é de entender a nossa realidade enquanto mulheres negras da Amazônia. Isso foi me deixando muito mais segura, foi o processo de autoestima sendo construído em cima da auto identificação negra até o ponto de falar que "eu sou negra e ponto" não sou morena, sou negra. Isso foi um processo que foi envolvendo muitos desses debates, e quanto mais debates eu participava, mas eu me sentia segura de afirmar essa negritude. Quanto mais eu conversava, mais eu dialogava, mais eu me sentia bem na questão da minha auto afirmação até o ponto de eu entrar no movimento negro e me sentir acolhida de forma plena sobre ser negra e ser mulher. (Entrevista, 2019).

Zaíta levanta uma questão importante na fala anterior: dentro do movimento negro com que teve contato em Belém, sente-se confortável para se identificar como negra, ainda que em muitos momentos seja lida como morena na cidade justamente por conta da ideia de que existe uma morenidade a ser compartilhada, ideia essa que é cada vez mais combatida pelo movimento negro em Belém, que tem como empenho a educação de pessoas negras sobre suas identificações raciais. Em outro momento, ela conta que, fora de Belém, sua identificação enquanto negra também foi muitas vezes questionada. Afirma:

Teve um momento que eu me identifiquei muito mais por indígena do que como morena ou negra. Quando eu fui para Imperatriz, eu ouvi as pessoas falando "aquela menina tem cara de índia", "a senhora tem cara de indígena". Então, a identidade indígena, em um momento muito pequeno da minha vida, era muito mais aceitável que a negra... Até porque tinha cabelo alisado, muito comprido, então, aí pegava muito aquele estereotipo (Entrevista, 2019).

Aqui, fica explícito que esse indígena ancestral que os não amazônidas tentam alcançar para tipificar pessoas dessa região é uma imagem fixa, romantizada, um estereótipo do que o indígena seria. O que apontam como índia ou indígena é algo que se reduz em sua própria imagem, que não tem complexidade 
para além do que os olhos alcançam. E não apenas Zaíta faz relatos como esse; de fato, eles são repetidos em outras palavras e dimensões, por outras interlocutoras. Em rodas de conversa, em momentos de pesquisa de campo, por vezes mulheres negras belenenses se queixaram sobre a maneira como mulheres brancas e negras não amazônidas apontavam e decidiam ter o direito de definir ou não a negritude de mulheres negras daqui. Não estamos falando de mulheres que não são negras, mas de mulheres amazônidas que têm sua negritude reconhecida por outras mulheres negras amazônidas e, portanto, completas em suas identificações raciais no que tange ao reconhecimento individual e de grupo, mulheres que estão articuladas em diversas e reconhecidas redes de militância do movimento negro e feminista na cidade.

O que faz com que mulheres daqui não sejam lidas como negras não é apenas a pele clara ou os traços "diferentes", mas o fato de não corresponderem ao estereótipo que foi construído sobre a Amazônia: não são mulheres indígenas, ainda que carreguem, no corpo, traços dessa ancestralidade ou daquilo que corresponde ao estereótipo assumido nacionalmente sobre o que essa ancestralidade seria. Assumir a morenidade como categoria possível e negar a negritude de pessoas amazônidas, cujas autodefinições estão bem resolvidas, são movimentos diferentes que respondem à mesma tentativa de negação identificatória e, por vezes, as mulheres negras de pele clara dessa região se veem tendo que responder simultaneamente a essas duas dinâmicas de invisibilização e violência. De acordo com as experiências relatadas sobre esse embate com o olhar do outro que, ainda que negro, não é amazônida, mulheres negras de pele clara daqui não são consideradas negras por terem traços "diferentes" e seus traços "diferentes" são impeditivos para que sejam lidas em sua 'raça', mas não o são para que sejam lidas em relação ao território: não é negra, é amazônida; essas mesmas mulheres, quando na Amazônia, são lidas socialmente "morenas" e não como negras.

Segundo Loureiro (2004, p.51) homem e natureza na Amazônia têm sido construídos por um duplo movimento: apropriação privada da natureza que transforma a natureza e seus bens em mercadoria; e a transformação do trabalho do homem, em que tanto maior é o tempo dispensado em produção de mercadoria, gradativamente vai ele mesmo se transformando em mercadoria. O Estado ora é omisso sobre as relações de trabalho, ora se declara favorável ao grande capital, seguindo a lógica de que "o progresso advém da aplicação exclusiva do capital e não como fruto do trabalho humano" (p.60). A região foi integrada à nação não como parte da nação, mas como mercadoria para consumo do mercado nacional no que tange às outras regiões do país e mercado internacional (p.66). Nesse contexto, as representações predominantes da (e sobre) a Amazônia são de um lugar para ser consumido, produto desatrelado de povo, de cultura, de espaço de produção de cultura e narrativas. As representações feitas sobre a população são de exotismo, de pessoas indígenas que são, ainda, produto para consumo quando o interesse é pelo exótico.

Segundo Bourdieu (1989, p.114-115), fronteiras não são mais que divisões produzidas de maneira não natural. O que define uma região é a semelhança de elementos mais ou menos parecidos de acordo com critérios que são muitas vezes imprecisos - as características "naturais" que aproximam são imposições arbitrárias fortemente influenciadas pelas relações de força estabelecidas em determinado campo. Fronteira é 


\section{Na Amazônia, em Belém, no encontro com outrem}

uma delimitação jurídica que produz e é produto de diferenças culturais. Esse é o caso do espaço amazônico, que se construiu na diferença colonial, carregado de exotismo e marcado por hierarquias sociais e culturais (gênero, cor/raça, nação, região), e que constitui, ainda hoje, como um campo de disputas por controle das representações, classificações, nomeações e identificações, pelos agentes, em suas práticas cotidianas.

Quando se fala em espaço social, deve-se compreender que grupos se aliam de acordo com seus interesses por princípios fundamentais de divisão que hierarquizam espaços sociais. A luta política está no conhecimento do mundo social e suas relações de transformação e manutenção de estruturas de poder. Determinadas identidades sociais possibilitam a alguns agentes no campo de forças o direito de categorizar, classificar, nomear - ou melhor, faz com que determinados agentes se sintam nesse direito. Esse poder de constituir os grupos, o senso comum e até mesmo o consenso dentro dos grupos é um importante poder social e político (BOURDIEU, 1989). O poder político de nomear (BOURDIEU, 1989, p.146,236) é expressão de dominação simbólica organizada a partir de uma lógica de diferenças. O espaço social e os grupos que nele habitam são caracterizados pelos estilos de vida diferentes que assumem e, nesse espaço, quem possui maior poder simbólico constrói as hierarquias).

Ao transpor essa lógica para a disputa por nomeação de quem é negro ou não dentro do campo do movimento negro em nível nacional, é possível perceber, a partir de pesquisa etnográfica, que analistas não amazônidas, negam a existência de uma negritude amazônida. Tal como em outros momentos da história, um olhar externo é imposto à nossa região como espaço distante, diferente, exótico, algo que não pode ser explicado ou compreendido por suas similaridades, mas apenas em sua diferença. Como um país de tamanho continental e absolutamente diverso no que tange a tradições culturais e expressões fenotípicas, o Brasil tem sua história oficial contada a partir do protagonismo dos eixos sul e sudeste, e esse movimento construiu uma história única e incompleta sobre a região e, por vezes, falaciosa.

Histórias incompletas não o são sem resistência, exemplo disso foi o que aconteceu com o movimento feminista quando, a partir da terceira onda, de maneira mais visível (com mais ampla escuta), provocou a necessidade de se pensar um feminismo negro, indígena, de mulheres do campo e outras vertentes que pudessem dar conta das especificidades e desfazer os universalismos criados na categorização de um tipo único de mulher (PINTO, 2003). Acreditamos que a lógica colonial sobre a Amazônia acabou sendo transportada até mesmo para dentro de movimentos que se pretendem libertadores, como o movimento negro que, de acordo com o que foi relatado, ainda tem dificuldade em lidar com as diferentes noções de negritude que se apresentam por aqui.

Uma das interlocutoras de Flávia Câmara (2017, p.152) e, de acordo com a autora, 'preta retinta', conta que:

[...] sobre a nossa identidade, sobre ser mulher negra na Amazônia é muito doido, porque digamos quando eu tô fora do Pará nunca pensam que eu sou paraense, sempre perguntam se eu sou carioca ou se eu sou baiana, ou maranhense, aqui inclusive pela fala, pela aparência e tudo, aí quando tu diz "não, eu sou do Pará", eles ficam assim "mas lá não é só índio?". Não gente, existe toda uma formação indígena e afro na Amazônia como um todo $[\ldots]$. 
Por ter a pele escura e traços que supostamente não lembrariam uma ancestralidade indígena, não é lida como paraense, mas o é como negra. As mulheres interlocutoras dessa pesquisa não compartilham desse tipo de experiência por serem negras de pele clara, de olhos "puxadinhos", por não serem vistas como próximas fenotipicamente das negritudes do outro lado do país e até mesmo aqui do lado, no Nordeste. São mulheres que reivindicam a negritude também em relação ao espaço que ocupam, a região amazônica, em um movimento de afirmação de si e do espaço enquanto protagonistas em uma narrativa própria. Falando sobre o Encontro Nacional de Mulheres Negras que aconteceu em 2019, Luamanda afirma:

A região Norte, nos encontros, eu percebo que a gente sempre passa por isso e é muito perceptível, não só na minha visão como de ouvir de outras mulheres, no próprio encontro houve momento de tensão com a delegação do Pará e de outros estados também em relação a isso, de dizer que "ai, tu sofre menos racismo que eu porque eu sou retinta", "imagina eu que sou mais retinta". Tem toda essa questão também de nível de Brasil a de não perceber o Pará como estado de negros que agora no IBGE mostrou que o Pará se declarou mais negro que o próprio Salvador, o Pará se declarou mais negro que a Bahia e tem que ver a questão não enxergar Belém, o Pará como um estado de negras e negros, de passar mais pela questão indígena.

No encontro Nacional aconteceu com algumas meninas, eu não estava no momento, quando eu cheguei já tinha ocorrido uma tensão. Depois eu participei da reunião pra discutir sobre que teve que fazer sobre essa conversa, sobre essa questão de colorismo que rolou entre delegações do Rio, do Pará, do Espirito Santo. Foi mais a questão do colorismo. "Eu que sou mais escura sofro mais racismo que tu", de medir quem sofre mais, eu ou tu. Por eu ter um tom de pele mais claro e "tu imagina eu, que sou retinta, sofro mais que tu". Foi isso de medir racismo, medir dor. Não, né? Não cabe pegar pra medir a minha dor ou a tua dor, de quem sofre mais ou menos que eu. A gente tá ali em busca de algo coletivo, de buscar a superação juntas (Entrevista, 2019).

Todas as mulheres entrevistadas compreendem que quanto mais marcados forem os traços negros no fenótipo, mais situações de violência essa pessoa pode passar, uma vez que, no Brasil, existe um preconceito de marca (NOGUEIRA, 2006), ou seja, como resposta racista ao fenótipo. Quando Luamanda e outras mulheres dizem que se incomodam com o fato de que não serem identificadas como negras por terem a pele mais clara, é porque compreendem a negação da identificação como um processo que também é muito violento, e pelo qual passaram grande parte da vida nessa cidade que, de modo muito específico, as morenizou.

Quando Luamanda afirma que não se mede sofrimento, está contando não só do que vê como falha na maneira como outra pessoa se posiciona frente à situação posta, mas de uma angústia de alguém que teve todo um passado negado de ser vivido na identidade que assume agora e por não conseguir desatrelar a identificação racial da identificação regional. É negra e amazônida, e enquanto uma mulher não amazônida passa por situações de violência por ser 'retinta', ela passa por situações de violência por ser negra da Amazônia e ter, no corpo e no espaço que habita, de se ver com as dinâmicas dessas identificações. Todas as vezes que falam sobre as angústias de encontros com pessoas não amazônidas que não respeitavam a 


\section{Por acaso sou negra?}

\section{Na Amazônia, em Belém, no encontro com outrem}

autoidentificação dessas mulheres ou tentavam dizer que elas "sofriam menos" por terem a pele mais clara, essas angústias não se desatrelavam da noção de serem amazônidas e, de alguma forma, estarem na periferia do Brasil, em situação de exploração.

Para Bourdieu (1989), não é possível fazer uma ciência das classificações sem que seja pensada a luta por essas classificações considerando a posicionalidade de cada agente no campo, o uso do conhecimento, do poder pelo conhecimento e do monopólio da violência simbólica legítima. Kilomba (2019, p.111), contando sobre Alicia, mulher afro-alemã, afirma que o racismo é explicitado em termos de territorialidade quando olham para essa mulher e não veem nela alguém que possa ser alemã, quando sua nacionalidade é questionada por ela ser negra. O questionamento se configura como forma de lembrar o seu não pertencimento, é uma “construção na qual 'raça' é imaginada dentro de fronteiras nacionais específicas e nacionalidade em termos de 'raça'". Ou se é negra ou se é alemã.

Quando dizem para Alicia que os traços dela não combinam com sua nacionalidade, estão colocando-a para fora da nação, dizendo-lhe que ela não combina com sua cultura, informando-lhe que a sua diferença lhe faz estar fora do lugar - "você não é alemã!". Ela tem, em qualquer momento, em qualquer lugar, sua biografia questionada por sujeitos brancos nessa lógica dialética colonial onde o sujeito branco é autoridade absoluta e se sente à vontade para perguntar "o que eu vejo?", enquanto ela, enquanto pessoa negra é forçada a se perguntar "o que elas/eles veem?" (KILOMBA, 2019, p.116). Acreditamos que a lógica de tipificação ou não da negritude de pessoas negras de pele clara da Amazônia perpassa por caminho inverso ao da experiência de Alicia na Alemanha: enquanto ela é colocada para fora da nação por sua raça, aqui temos que pessoas são colocadas para fora da raça por não serem consideradas como parte da nação.

Às mulheres negras é imposta condição de recorrente negociação entre o que se é e as maneiras como os outros a enxergam, por isso a questão da autodefinição é tão cara. Auto definir-se significa livrar-se das opressões internalizadas, como as opressões impostas pela morenidade, por exemplo. Quando essas mulheres negras sentem que suas autodefinições não são respeitadas, é como se voltasse à memória todas as vezes que elas foram desrespeitadas na vida por sua raça e região, de modo que o que se ouve se transforma em angústia, e por vezes até em raiva, pela violência da palavra proferida por esse outro que as deslegitima, ainda que sabendo que estão legitimadas por outras mulheres que lhes são pares.

\section{CONSIDERAÇÕES FINAIS}

A população da Amazônia ainda é lida e definida em relação ao espaço, tendo sua subjetividade impedida pela mesma representação que sustentou e sustenta lógicas de exploração em nossa região: quem vem de fora detém o direito de definir quem somos, o que temos e o que é melhor para nós. É possível inferir que, em alguma medida, a categoria de morenidade que trouxemos para esse artigo ganha força a partir de um olhar de fora também, uma vez que o embranquecimento foi projeto de nação e em grande parte da história brasileira a região Amazônica não foi vista como parte da nação; em termos práticos, para além de estereótipos, de fato não é até hoje. Identificar-se como negra em uma cidade tão morenizada como é Belém, 


\section{Por acaso sou negra?}

\section{Na Amazônia, em Belém, no encontro com outrem}

faz parte de um movimento de negação às tentativas de embranquecimento, de anulação de negritude. Ao mesmo tempo, identificar-se como negra frente a não amazônidas é se desvencilhar de amarras coloniais e combater o movimento colonial de silenciamento de vozes amazônidas.

Definir a si mesma, definir quem se é só ganha sentido de autonomia quando o reconhecimento de si está relacionado à noção de continuidade com a comunidade; a autodefinição só é autônoma quando relacionada com o coletivo e tem como ponto de partida a positivação de uma identidade, tem a ver com autovalorização (COLLINS, 2019). E é em espaços seguros, espaços em que podem conversar entre iguais que essas mulheres resistem à objetificação. Segundo a autora, "ao promover o empoderamento das mulheres negras por meio da autodefinição, esses espaços seguros as ajudam a resistir à ideologia dominante promulgada não apenas fora da sociedade civil negra, mas também dentro das instituições afro-americanas" (COLLINS, 2019, p.185); no nosso caso, as instituições afro-brasileiras.

O que se apresenta nas falas das interlocutoras, no entanto, é que por ser essa hierarquização fruto de processos de colonização dentro da colônia - a região amazônica como espaço duplamente colonizado -, isso faz com que a noção de afrobrasilidade não seja suficiente. É por isso que, aqui, a identidade afroamazônida vem sendo construída há tempos pelo movimento negro nessa região, e cada vez mais se consolidando como categoria identificatória, categoria essa que por vezes é reivindicada pelas interlocutoras entrevistadas nessa pesquisa. Essa necessidade de afirmação regional acontece para que sejam marcadas as condições específicas da intersecção entre a identidade racial e a identidade da região que constrói essa terceira identidade híbrida, um ser afroamazônida, identidade essa que a noção de afro-brasileiro não tem dado conta por não explicitar essas lógicas de poder dentro do próprio território nacional, tal como apontadas anteriormente, além de ser um posicionamento político de autodefinição. A autodefinição é uma estratégia importante de agência e resistência às opressões.

Definir o que é ser afroamazônida é trabalho para uma vida inteira. Aqui, arriscamos dizer que essa identificação híbrida, fruto de muitas lutas, é ferramenta política de auto definição de pessoas negras amazônidas frente aos processos de invisibilização de negritudes nesse espaço. É negação de uma morenidade que impede identificações com negritude e, portanto, resistência a violências que antes não podiam ser nomeadas. É resposta para quem ainda tem dificuldade em enxergar a Amazônia para além das representações exotizadas e mercantilizadas que resultam na exploração de recursos naturais e humanos, colocando em posição de marginalidade populações tradicionais negras amplamente vitimadas pelos grandes projetos na Amazônia. É, sobretudo, política. A linguagem também é um lugar de luta.

\section{REFERÊNCIAS}

BAUMAN, Zigmunt. Identity in the Globalising World. Social Anthropology, Castelgandolfo, n. 9, v. 2, p. 121-129, 2001.

BOURDIEU, Pierre. O Poder Simbólico. Lisboa: DIFEL, 1989. 312p. 
CÂMARA, Flávia Danielle da Silva. Mulheres negras amazônidas frente à cidade morena: o lugar da psicologia, os territórios de resistência. Dissertação (Mestrado em Psicologia). Belém: PPGP/IFCH/UFPA, 2017. 216p.

CARDOSO DE OLIVEIRA, Roberto. Caminhos da Identidade: ensaios sobre etnicidade e multiculturalismo. São Paulo: Editora Unesp; Brasília: Paralelo, 2006. 256p.

CASTELLS, Manuel. O Poder da Identidade. São Paulo: Paz \& Terra. 2008. 530p.

CASTRO, Fábio Fonseca. Entre o mito e a fronteira. Belém: Labor Editorial, 2011. 282p.

COLLINS, Patricia Hill. Pensamento Feminista Negro: conhecimento, consciência e a política do empoderamento. 1. ed. São Paulo: Boitempo, 2019. 480p.

CONRADO, Mônica; CAMPELO, Marilu; RIBEIRO, Alan. Metáforas Da Cor: Morenidade e territórios da negritude nas construções de identidades negras na amazônia paraense. Afro-Ásia, Salvador, n. 51, p. 213246, 2015.

FANON, Franz. Pele negra, máscaras brancas. Salvador: EDUFBA, 2008. 192p.

GOMES, Flávio dos Santos. "Amostras Humanas”: índios, negros e relações interétnicas no Brasil colonial In: MAGGIE, Yvonne; REZENDE, Cláudia Barcellos (Org.). Raça Como Retórica: A construção da diferença. Rio de Janeiro: Civilização Brasileira, 2001, p. 27-81.

GUIMARÃES, Antônio Sérgio Alfredo. Formações nacionais de classe e raça. Tempo Social: revista de sociologia da USP, São Paulo, v. 28, n. 2, p. 161-182, agosto 2016.

HASENBALG, Carlos. Discriminação e Desigualdade raciais no Brasil. Rio de Janeiro: Graal, 1979. 316p.

IBGE. Censo Demográfico 2010: Características Gerais da População, Religião, e Pessoas com Deficiência. Rio de Janeiro: IBGE, 2010. 211 p.

KILOMBA, Grada. Memórias da Plantação: episódios de racismo quotidiano. Lisboa: Orfeu Negro, 2019. $246 \mathrm{p}$.

LOPES, Joyce Souza. Lugar de branca/o e a/o "branca/o fora do lugar: representações sobre a branquitude e suas possibilidades de antirracismo entre negra/os e branca/os do/no Movimento Negro em Salvador-BA. Dissertação (Mestrado em Antropologia Social). Pelotas: PPGAS/UFPel, 2016. 255p.

LORDE, Audre. Idade, raça, classe e gênero: mulheres redefinindo a diferença. In: HOLLANDA, H. B. Pensamento Feminista: conceitos fundamentais. Rio de Janeiro: Bazar do Tempo, 2019, p. 239-250.

LIMA-AYRES, Deborah. A construção histórica da categoria caboclo. Sobre estruturas e representações sociais no meio rural. Novos Cadernos NAEA, vol. 2, nº 2, p. 5-32,1999.

LOUREIRO, Violeta Refkalefsky. Amazônia, Estado, Homem e Natureza. Belém: CEJUP, 2004. 342p.

MALDONADO, Mauro. Arquipélago identidade. O declínio do sujeito autocêntrico e o nascimento do eu múltiplo. Revista Latinoamericana de Psicopatologia Fundamental, São Paulo, Ano 8, n.3, p. 480-496, set. 2005. 
MOTTA-MAUES, Maria Angelica. Negro sobre negro: a questão racial no pensamento das elites negras brasileiras. (1930-1988). Tese (Doutorado em Sociologia). Rio de Janeiro: Instituto Universitário de Pesquisa do Rio de Janeiro - IUPERJ, 1997.

NOGUEIRA, Oracy. Preconceito racial de marca e preconceito racial de origem: Sugestão de um quadro de referência para a interpretação do material sobre relações raciais no Brasil. Tempo Social, v. 19, n. 1, p. 287308, Jan.-abri. 2006. 329p.

PAIXÃO, Marcelo; CARVANO, Luiz M. Censo e demografia: a variável cor ou raça no interior dos sistemas censitários brasileiros. In: PINHO, O.; SANSONE, L. (Orgs.) Raça: novas perspectivas antropológicas. 2. ed. rev. Salvador: EDUFBA, 2008, p. 25-61.

PINTO, Céli Regina Jardim. Uma História do Feminismo no Brasil. São Paulo: Fundação Perseu Abramo, 2003. 120p.

RIBEIRO, Alan Augusto. Sobre uma "pedagogia da morenidade": gênero e mestiçagem entre estudantes de duas escolas de Belém do Pará. Revista Acadêmica de Educação do ISE Vera Cruz, São Paulo, v. 2, n. 1, p. 114-129, 2012.

RODRIGUES, Carmem Izabel. Caboclos na Amazônia: a identidade na diferença. Novos Cadernos NAEA. Belém, V. 9, n 1, p.119-130, jun. 2006.

SALLES, Vicente. O Negro no Pará: sobre o regime da escravidão. Belém: IAP; Programa Raízes, 2005. $372 \mathrm{p}$.

SARRAF, Moisés Taate Alves. Cidade Morena. [online] Belém: Outro400.com.br, 2016. Disponível em: < http://outros400.hostbelem.com.br/especiais/3745>. Acessado em: 20 jan. 2019.

Belém também é afro: tensões discursivas na Amazônia urbana. Dissertação (Mestrado em Comunicação, Cultura e Amazônia). Belém: PPGCOM/ILC, UFPA, 2019. 112p.

SILVA, Tomaz Tadeu. A produção social da identidade e da diferença IN SILVA, Tomaz Tadeu; HALL, Stuart, WOODWARD, Kathryn. (Orgs). Identidade e Diferença: a perspectiva dos estudos culturais. Petrópolis, RJ: Vozes, 2014, p. 73-102.

VAZ SILVA, Tiago Luís Coelho. Ver-a-Cor: Um estudo sobre as relações raciais no mercado do Ver-o-Peso em Belém (PA). Dissertação (Mestrado em Antropologia Social). Florianópolis: PPGAS/UFSC, 2007. 117p.

VERGOLINO-HENRY, Anaíza.; FIGUEIREDO, Arthur Napoleão. A presença africana na Amazônia Colonial: uma notícia histórica. Belém: Arquivo Público do Pará, 1990. 280p.

WAGLEY, Charles. Uma comunidade amazônica: estudo do homem nos trópicos. São Paulo: Editora Nacional, 1977 [1956]. 312p.

WOODWARD, Kathryn. Identidade e diferença: uma introdução teórica e conceitual IN SILVA, Tomaz Tadeu; HALL, Stuart. WOODWARD, Kathryn (Orgs). Identidade e Diferença: a perspectiva dos estudos culturais. Petrópolis, RJ: Vozes, 2014, p. 7-72. 